\begin{tabular}{c} 
International Journal of Dental Research, $5(x)(2017)$ 103-107 \\
International Journal of Dental Research \\
Website: $\begin{array}{c}\text { ww. sciencepubco.com/index.php/IJDR } \\
\text { doi: } 10.14419 / i j d r . v 5 i 2.7662 \\
\text { Review Paper }\end{array}$ \\
\hline
\end{tabular}

\title{
Expand the constricted-review article
}

\author{
Sharath Kumar Shetty ${ }^{1}$, Roginth Vigneshwaran A ${ }^{2}$, Mahesh Kumar Y ${ }^{3}$, Vijayananda Madhur ${ }^{4}$ \\ ${ }^{1}$ Professor\& HOD, Department of Orthodontics and Dentofacial Orthopaedics, $K$ V G Dental College and Hospital, Sullia, Karnataka \\ ${ }^{2}$ Post Graduate Student, Department of Orthodontics and Dentofacial Orthopaedics, $K$ V G Dental College and Hospital, Sullia, Karnataka \\ ${ }^{3}$ Professor, Department of Orthodontics and Dentofacial Orthopaedics, $K$ V G Dental College and Hospital, Sullia, Karnataka \\ ${ }^{4}$ Reader, Department of Orthodontics and Dentofacial Orthopaedics, K V G Dental College and Hospital, Sullia, Karnataka \\ *Corresponding author E-mail: vickyspike19@gmail.com
}

\begin{abstract}
A combination of orthopaedic and orthodontic tooth movements are required for expansion of palate to correct maxillary transverse discrepancy. Expansion of the palate can be achieved by three different treatment methods mainly Rapid maxillary expansion, slow maxillary expansion and surgically assisted maxillary expansion. Among the different methods rapid maxillary expansion brings about significant changes in the dental transverse measurements (Agarwal A, Mathur R International journal of clinical pediatric dentistry 2010). This article aims to review the various appliances used for maxillary expansion.
\end{abstract}

Keywords: Maxillary Expansion; Types of Maxillary Expansion; Appliances Used for Maxillary Expansion

\section{Introduction}

Palatine bone forms intimate articulation with maxilla to form hard palate and greater part of lateral wall of nasal cavity. Palatine bone articulates with maxilla anteriorly through transverse palatal sutures and posteriorly through pterygoid process of sphenoid bone, the interpalatine suture joins the two palatine bones at their horizontal plates and continues as intermaxillary sutures(Kumar SA, Gurunathan D et al, Journal of clinical and diagnostic research 2011).Normal palatal growth is nearly complete by age 6(Moyers RE, Van der Linden et al craniofacial growth series,1976).Maxillary transverse deficiencies can be corrected by expansion of palate, which requires a combination of orthopaedic and orthodontic tooth movements. Treatment modalities currently used for correction of maxillary transverse deficiencies are rapid maxillary expansion, slow maxillary expansion and surgically assisted maxillary expansion. Appliances for expansion are selected based on the experience of the practitioner, patient's age and malocclusion( Ficarelli JP, J Pedod 1978 and Bell RA, Am J Orthod 1928). The clinical/major indications for maxillary expansion are correction of transverse discrepancies such as crossbite, cases requiring distal molar movement, to aid maxillary protraction, cases requiring correction of mild crowding(Agarwal A, Mathur R International journal of clinical pediatric dentistry 2010).This article aims to review the various appliance used for maxillary expansion.

\section{Appliances used for rapid maxllary expan- sion (RME)}

Appliances used for RME can be either banded appliance or bonded appliances.

$>$ Banded RME-TYPES:

1) Tooth and tissue born RME

- HAAS

- DERICHSWEILER
2) Tooth borne RME:

- HYRAX expander

- Issacson expander

$>$ Bonded Rapid palatal expander

$>$ IPC Rapid palatal expander

\section{Appliances for slow maxillary expansion (SME)}

1) Coffin appliance

2) W-arch

3) Quad Helix

4) Spring jet

5) NiTi Expander

\section{Tooth borne RME appliances}

1) HYRAX Expander:

Hyrax-Hygienic Rapid Expander. HYRAX is a tooth borne appliance introduced by William Biedermann in 1968. The HYRAX expander is essentially a non-spring loaded jackscrew with an all wire frame (Bishara SE Stanley RN,Am J Orthod Dentofacial Orthop 1987).Heavy gauge wire extensions are soldered to bands on premolars and molar and are adapted to follow the palatal contours. The screw is activated from front to back and produces $0.2 \mathrm{~mm}$ of lateral expansion.11-13 mm of sutural separation can be achieved with the help of HYRAX expander. 


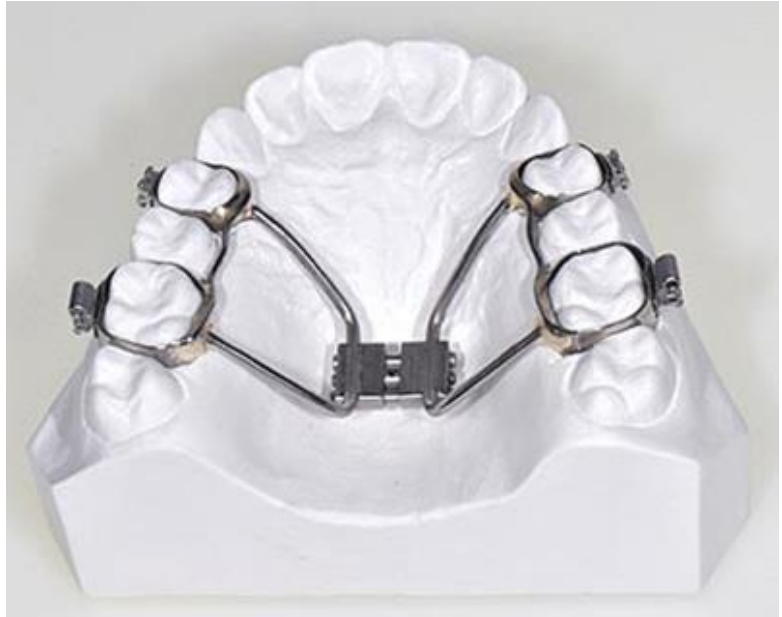

Fig. 1: Hyrax Expander.

2) Issacson Expander:

A special spring loaded screw called Minne expander (developed by university of Minnesota, dental school) is soldered directly to bands on first premolar and molars(Bishara SE Stanley RN,Am J Orthod Dentofacial Orthop 1987).The Minne expander is a heavily calibrated coil spring expanded by turning a nut to compress the coil and it continues to exert expansion forces after completion of the expansion phase unless they are partly deactivated.

\section{Advantages of tooth borne RME}

1) Tooth borne appliance are devoid of palatal covering and so no irritation to palatal mucosa.

2) Tooth borne appliances are easy to clean.

3) Minimal interference with speech.

\section{Tooth and tissue borne RME appliances}

1) HAAS:

The rapid palatal expander as described by Haas is a rigid appliance designed for maximum dental anchorage that uses a jackscrew to produce expansion in 10 to 14 days(Haas AJ ,Angle Orthod 1965).Forces produced by the appliance have been reported in the range of 3 to 10 pounds.

2) Derichsweiler:

Wire tags are soldered to bands on first premolar and molar and then inserted to the split palatal acrylic, which contains the screw.

\section{Advantages of tooth and tissue borne RME}

Haas in 1970 gave the following advantages

1) Creates greater mobility of maxilla instead of teeth

2) Favourable relationship of the denture base in width

3) Greater nasal cavity and apical base gain

4) Produces more parallel expansion

5) Less chance of relapse

\section{Disadvantages of tooth and tissue borne RME appliances}

Tooth and tissue born RME appliances consists of expansion screw with acrylic abutting on alveolar ridges and hence have a greater chances of soft tissue irritation.

\section{Bonded rapid palatal expander}

The bonded rapid palatal expander were first described by Cohen and Silverman in 1973.Acrylic cap is constructed over the posterior segments which are bonded directly to the teeth (Sarver, Am J Orthod Dentofacial Orthop1989).

\section{Advantages of bonded appliance}

1) It can be easily cemented during the mixed dentition stage, when retention from other appliances can be poor.

2) Number of appointments are reduced

3) There is reduced posterior teeth tipping and extrusion. The buccal capping limits molar extrusion during treatment and therefore improves the vertical control, which is particularly useful in class II conditions, as molar extrusion would auto rotate mandible backward and downward resulting in increase in facial convexityand the vertical dimension of the lower face(Sarver, Am J Orthod Dentofacial Orthop1989).

4) It provides bite block effect to facilitate the correction of anterior crossbite (McNamara)

\section{IPC rapid palatal expander}

IPC is designed mainly for orthopedic expansion along with labial alignment of incisors. As expansion occurs, the IPC controls the Ni$\mathrm{Ti}$ open coil spring force applied to the lingual surface of the anterior teeth.Wire around the distal end of the lateral incisors limits the midline diastema that often occurs during RPE treatment.

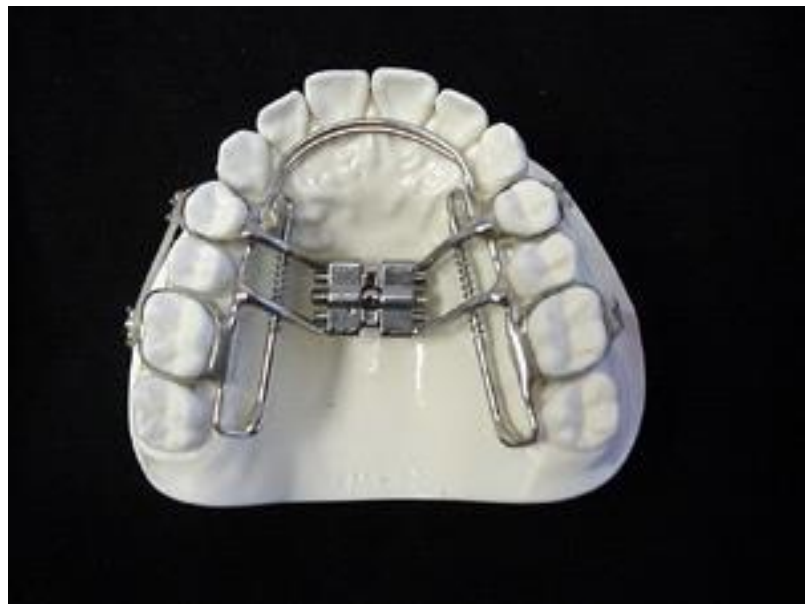

Fig. 2: IPC Rapid Palatal Expander.

\section{Advantages of screw type appliance}

1) Simple and well understood mechanics.

2) Allows clinician to prescribe a given number of activations to achieve specific expansion between patient visits.

3) Screw type appliance can be easily designed to be compact and light weight, which is a significant advantage in narrow maxilla (Romanyk DL Lagravere MO et al , J Dent Biomech 2010).

\section{Disadvantages of screw type appliances}

1) As maxilla is subjected to stepwise increments of the appliance which in turn causes rapid increases in force.This may be uncomfortable for the patient as well as results in less physiologic expansion of suture.

2) Method of appliance activation depends on patient's cooperation as it requires patient to activate the appliance (Romanyk DL Lagravere MO et al, J Dent Biomech 2010).

\section{Appliances in slow maxillary expansion}

\subsection{Coffin appliance}


It is a removable appliance capable of slow dentoalveolar expansion, given by Walter coffin - 1875.The appliance consists of an omega shaped wire of $1.25 \mathrm{~mm}$ thickness, placed in the midpalatal region. The free ends of the omega wire are embedded in acrylic covering the slopes of the palate. The spring can be activated by pulling two sides apart manually.

\subsection{W-Arch}

The 'W' expansion appliance was originally used by Ricketts and his colleagues (Ricketts RM Bench RW et al ,Rocky Mt Orthod 1979) to treat cleft palate patients. The $W$ arch is a fixed appliance constructed of 36 mil steel wire soldered to molar bands. The lingual arch is constructed such that it rests $1-1.5 \mathrm{~mm}$ off the palatal soft tissues. The appliance is activated by opening the apices of the $\mathrm{W}$-arch and is easily adjusted to provide greater anterior than posterior expansion. Expansion should continue at the rate of $2 \mathrm{~mm}$ per month until the crossbite is slightly overcorrected.

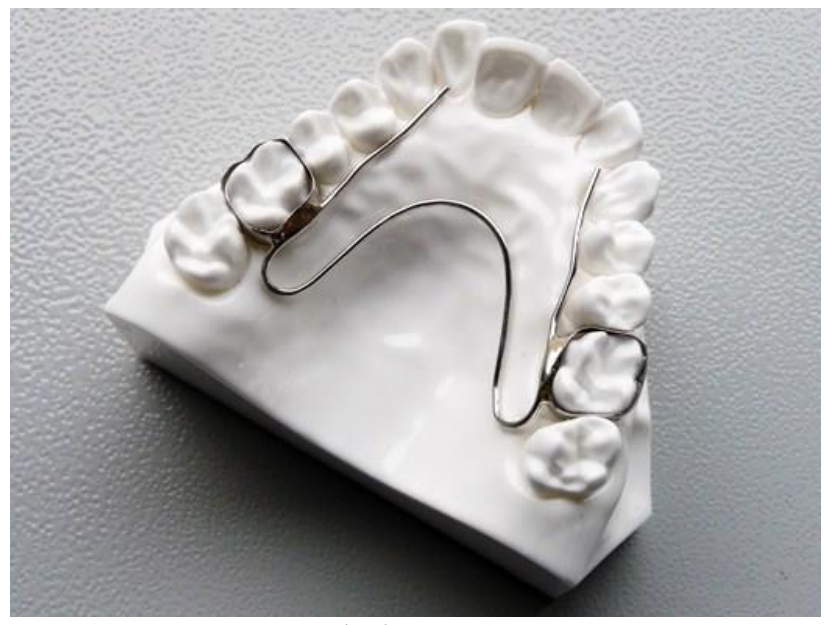

Fig. 3: W-Arch.

\subsection{Quad helix}

The quad helix appliance was described by Ricketts, which is actually a modification of coffin's W spring to increase flexibility and range of activation four helices were incorporated into the $\mathrm{W}$ spring. Prefabricated appliance constructed from nickel titanium have been introduced recently which has super elastic properties that can deliver favourable force.

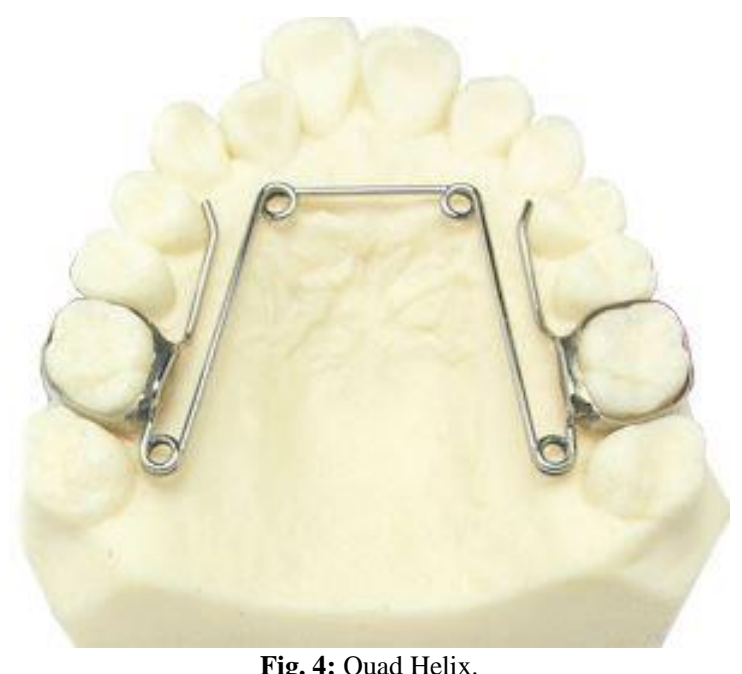

\subsection{Mode of action}

The quad helix appliance causes buccal tipping and skeletal expansion in a ratio of $6: 1$ in prepubertal children.

\section{Clinical management}

The appliance can deliver a desirable force level of 400 gm by activating it by $8 \mathrm{~mm}$, which equals to approximately one molar width. Patients should be reviewed on a six-weekly basis(Vardimon AD Graber, Am J Orthod Dentofacial Orthop 1987).Expansion should be continued until the palatal cusps of the upper molar meet edge to- edge with the buccal cusps of the mandibular molars. A threemonth retention period is recommended once expansion has been achieved with the quad helix in place.

\subsection{Advantages}
1) Good retention
2) Large range of action
3) Orthopaedic effect
4) Differential expansion
5) Habit breaker
6) Fixed appliances can be incorporated
7) Molar rotation/torque
8) Non compliance
9) Cost effective

\subsection{Disadvantages}

1) Molar tipping

2) Bite opening

3) Limited skeletal change

\subsection{Magnets}

Repulsive magnetic forces for maxillary expansion were first described by Vardemon et al in 1987(Vardimon AD Graber ,Am J Orthod Dentofacial Orthop 1987).Banded magnets produced more pronounced skeletal (compared to) versus overall expansion effects. The continuous force of 250-500gm could generate dental and skeletal movements.

\subsection{Advantages}

1) Magnets impart measured continuous force over a long period of time; hence the risk of external root resorption is decreased.

2) They are structurally stable in all directions which will aid in preventing undesirable results (Romanyk DL Lagravere MO et al, J Dent Biomech 2010)

\subsection{Disadvantage}

Magnets tend to be oxidized in the oral environment due to the potential formation of corrosive products but this can be overcome by coating magnets. Magnets are quite bulky as they must be adequately stabilized and contain stout guide rods to prevent the magnets becoming out of line and causing unwanted rotational movements.

\subsection{Spring jet}

The active components of the spring jet are soldered or attached to the molar bands. The telescopic unit is placed up to $5 \mathrm{~mm}$ from center of molar tubes so that the forces pass close to the center of resistance of maxillary teeth. Force applied in mixed dentition is $240 \mathrm{gm}$ and $400 \mathrm{gm}$ in the permanent dentition. Activation is done by moving the lock screw horizontally along the telescopic tube. A ball stop on the transpalatal wire allows the spring to be compressed. 


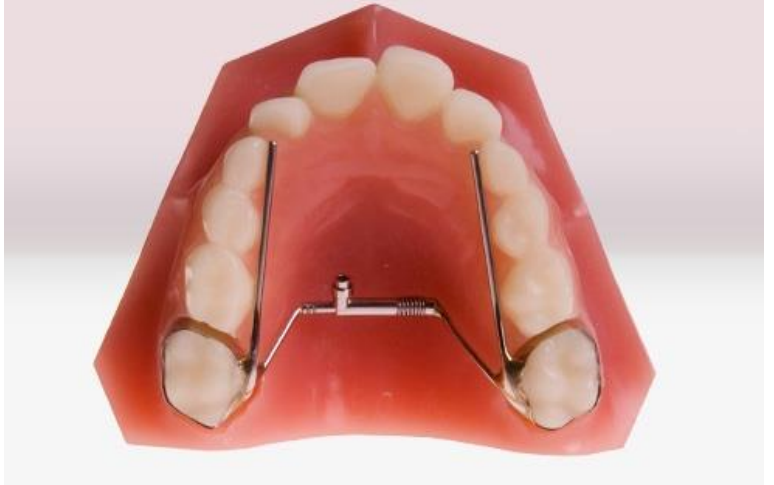

Fig. 5: Spring Jet.

\section{Advantages of spring type appliances}

1) Continuous force application throughout treatment.

2) Minimises the amplitude of force exerted on the tissue which may lead to more physiologic expansion and increased comfort.

3) Elimination of patient involvement for activation of appliance (Romanyk DL Lagravere MO et al, J Dent Biomech 2010)

\section{Disadvantages of spring type appliances}

1) Intermediate activations are required to maintain the necessary force magnitude to cause expansion.

2) They are structurally weak in the directions transverse to expansion (Romanyk DL Lagravere MO et al , J Dent Biomech 2010)

\section{NITI expander}

The nickel titanium palatal expanders were introduced by Wendell V (Wendell,JCO 1993).It generates optimal,constant expansion forces. The central component is made of a thermally activated NiTi alloy and the rest is made of stainless steel.The action of the appliance is a consequence of nickel titanium's shape memory and transition temperature effects(Robert Mazban ,JCO 1999).The nickel titanium component has a transition temperature of $94^{\circ} \mathrm{F}$.

At room temperature, the expander is too stiff to bend for insertion.Chilling the expander softens the central component allowing easy manipulation. Once placed, stiffens and begins to return to its original shape.A $3 \mathrm{~mm}$ increment of expansion exerts only about $350 \mathrm{gm}$ of force (Robert Mazban, JCO 1999). and the nickel titanium alloy provides relatively uniform force levels as the expander deactivates.

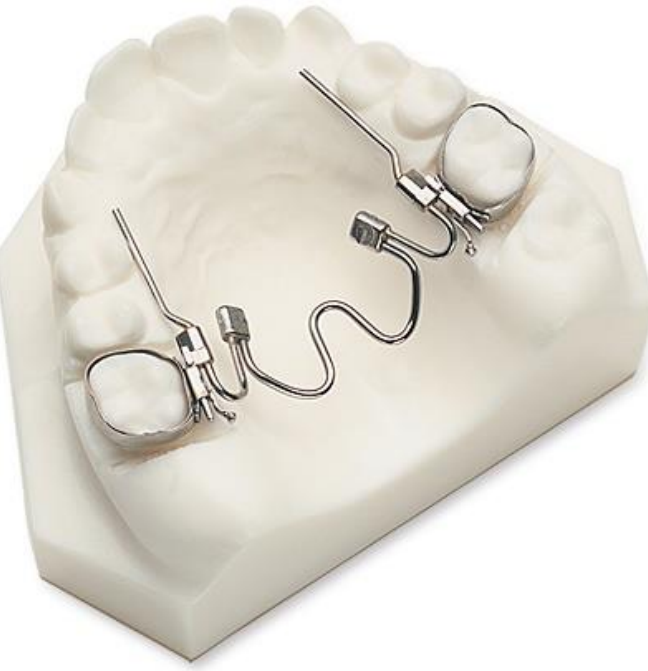

Fig. 6: NITI Expander.

\section{Disadvantages of shape memory alloy appliances}

1) Wire spring devices lacks structural stability in the directions transverse to the direction of expansion.

2) Patients are significantly involved in treatment and must activate the screws themselves (Romanyk DL Lagravere MO et al, J Dent Biomech 2010).

\section{Conclusion}

The type of skeletal and dental pattern greatly influences the type of expansion chosen and the type of expansion selected can greatly facilitate the overall treatment objectives. Selection of the appliance is multifactorial and nevertheless a clinician's skill is vital for the better treatment outcome.

\section{Acknowledgements}

Words cannot express my sincere gratitude to my renowned teacher, mentor and guide Dr. Sharath Kumar Shetty, Professor and Head of Department of Orthodontics and Dentofacial Orthopaedics, K V G Dental College \& Hospital, Sullia, for his timely advice, tolerance, guidance and encouragement he imparted during the period of this study.

I will forever be obliged to my revered Professors Dr. Mahesh Kumar Y and Dr. Vijayananda Madhur, Department of Orthodontics and Dentofacial Orthopaedics, K V G Dental College \& Hospital, Sullia, for their infinite patience, constant encouragement, timely reminders and support during the period of this study.

A word of appreciation for Er .Vishnupriya A, Dr.Pankaj, who spared their valuable time generously to lessen my burdens. Their encouraging words have helped me in many ways.

\section{References}

[1] Bell RA (1928) a review of maxillary expansion in relation to rate of expansion and patient's age. Am J Orthod, 81:1:32-7. https://doi.org/10.1016/0002-9416(82)90285-8.

[2] Haas AJ (1965) the treatment of maxillary deficiency by opening the midpalatalsuture .Angle Orthod, 35:200-17.

[3] Moyers RE, Van der Linden et al (1976) Standards of human occlusal development, Monraph 5, Craniofacial growth series, Center for Human Growth and Development,University of Michigan, Ann Arbor

[4] Ficarelli JP (1978) a brief review of maxillary expansion. J Pedod, $3: 1: 29-35$.

[5] Ricketts RM, Bench RW et al (1979) Bioprogressive therapy, Rocky Mt Orthod, 1:255-58.

[6] Bell RA, Le Compte EJ (1981) the effects of maxillary expansion using a quad helix appliance during the deciduous and mixed dentitions. Am J Orthod, 79:152-61? https://doi.org/10.1016/00029416(81)90313-4.

[7] Bishara SE, Stanley RN (1987).Maxillary expansion:clinical implicatons . Am J Orthod Dentofacial Orthop, 91:3-14? https://doi.org/10.1016/0889-5406(87)90202-2.

[8] Vardimon AD, Graber (1987) Magnetic versus mechanical expansion with different force thresholds and points of force application.Am J Orthod Dentofacial Orthop, 92:455-66. https://doi.org/10.1016/0889-5406(87)90227-7.

[9] Sarver (1989) Skeletal changes in vertical anterior displacement of maxilla with rapid palatal expander appliances. Am J Orthod Dentofacial Orthop, 462-66. https://doi.org/10.1016/08895406(89)90409-5.

[10] Wendell (1993) Nickel titanium palatal expander. JCO, 27(3):12937.

[11] Robert Mazban (1999) slow maxillary expansion with nickel titanium. JCO 33(8):431-41.

[12] Agarwal A, Mathur R (2010) Maxillary Expansion. International journal of clinical pediatric dentistry, 3(3):139-146. https://doi.org/10.5005/jp-journals-10005-1069. 
[13] Romanyk D L, Lagravere M O et al (2010) Review of Maxillary Expansion Appliance activation methods: Engineering and Clinica Perspectives. J Dent Biomech. https://doi.org/10.4061/2010/496906.

[14] Kumar S A, Gurunathan D et al (2011) Rapid Maxillary Expansion. A Unique Treatment Modality in dentistry. Journal of clinical and diagnostic research, 5(4):906-911. 